\title{
Characteristics of Long-Term Live-Donor Renal Allograft Survivors
}

\author{
Amgad E. El-Agroudy Mohamed A. Bakr Nabil A. Hassan Amani M. Ismail \\ Bedeir Ali-El-Dein Ahmed B. Shehab El-Dein Mohamed A. Ghoneim \\ Urology and Nephrology Center, University of Mansoura, Mansoura, Egypt
}

\section{Key Words}

Renal allograft · Long-term survival

\begin{abstract}
Background/Aims: Despite the high rate of rejection, allograft failure and patient mortality in the early years of renal allotransplantation, some patients have done-remarkably well. We report here on 62 renal transplant recipients out of 144 patients (43\%) who had functioning grafts for more than 15 years (range 15-24 years). Materials: Demographic and follow-up data for patients fulfilling the criteria were reviewed. These patients include 43 males and 19 females, with a mean age at transplantation of $27.5 \pm 6.6$ years (range 9-43 years), and mean donor age of $30 \pm 8.6$ years. The donor source was 8 parents, 49 siblings and 5 unrelated. The main causes of end-stage renal disease were chronic pyelonephritis and chronic glomerulonephritis. Twenty-nine patients were treated with cyclosporine (CsA) while 33 patients were primarily immunosuppressed by steroids and azathioprine. Results: Acute rejection episodes occurred in 40 patients $(64.3 \%)$, out of them 19 patients experienced two or more acute rejection episodes. Univariate analysis showed that recipient and donor age, HLA-DR matching, pre- and post-transplant hypertension, ATN,
\end{abstract}

delayed diuresis and chronic allograft nephropathy are significant risk factors; while recipient age, delayed diuresis and post-transplant hypertension were still significant by multivariate analysis. Conclusions: We concluded that renal transplantation, even in its earliest years and despite the numerous complications, has provided 15 or more years of near-normal life to patients with endstage renal disease. Certain characteristics of long-term renal allograft survivors include young donor/recipient pairs, good DR matching with less pre- and post-transplantation prevalence of hypertension.

Copyright @2003S. Karger AG, Basel

\section{Introduction}

Kidney transplantation restoring continuous renal functions represents the most physiological replacement therapy for end-stage renal disease. The goal of renal transplantation is to relive patients of the burden of dialysis and to allow returning to productive life. When compared with patients on dialysis, recipients of successful transplants enjoy a higher quality of life, which for obvious reasons is directly linked to the continued function of the graft [1].

\section{KARGER \\ Fax +4161306 1234 \\ E-Mail karger@karger.ch \\ www.karger.com

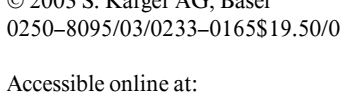

Dr. Amgad E. El-Agroudy

Urology and Nephrology Center

Mansoura University

Mansoura (Egypt)

Tel. +2 050 2262222, Fax +2 050 2263717, E-Mail amgadelbaz@ahram0505.net 
During the last two decades, a significant progress has been achieved in the graft and patient survival rates after renal transplantation [2]. Although numerous studies on 5- and 10-year survival of kidney grafts and their recipients have been published, data at 15 years or more are scarce. The factors influencing long-term survival of the graft are still being debated and the only fully accepted one is kidney origin, i.e. living donor surviving longer than cadaver. As the goal of transplantation should not be to provide a patient with a functioning graft for only 1 or 2 years but rather to offer a long-term resolution of the renal disease, we have analyzed the characteristics, nature of complications observed and factors which may influence long-term live-donor allograft survivors with an allograft that functioned for 15 years or more after renal transplantation.

\section{Patients and Methods}

\section{Patients}

Between March, 1976 and December 31, 1985, a total of 144 livedonor kidney transplants were performed at the Urology and Nephrology Center, Mansoura University. Of these, 62 kidney transplant recipients with a functioning graft for at least 15 years were the material of the study. Details of demographic data and surgical techniques and follow-up data were reviewed.

\section{Pre-Transplantation Work-Up}

Pre-transplant data were collected regarding schistosomal infection, original kidney disease, presence of hypertension, donor source, transplant received, blood group, and number of blood transfusions.

\section{Immunological Work-Up}

The HLA profile of our kidney transplant recipients has been analyzed. Tissue typing for class I and II antigens was done by the lymphocytotoxicity test. Lymphocytes were isolated from whole peripheral blood by density-gradient centrifugation on Ficoll-Hypaque class I typing was done using the complement-dependent lymphocytotoxicity test: NIH standard method. Class II typing was performed on B cells which were isolated by immunomagnetic beads.

\section{Immunosuppression Protocols}

Our immunosuppressive protocols have previously been described in detail [3-5] from 1970s till the 1990s. All patients, before 1983, received azathioprine $(2-3 \mathrm{mg} / \mathrm{kg} /$ day) and prednisolone ( $2 \mathrm{mg} / \mathrm{kg} / \mathrm{day}$, with subsequent tapering of the dose till $0.5 \mathrm{mg} / \mathrm{kg} / \mathrm{day}$ after 1 month). After 1983, other protocols were evolved over time. Cyclosporine (CsA) was introduced, with two main protocols CsA $12 \mathrm{mg} / \mathrm{kg} /$ day and prednisolone, or triple therapy CsA $(10 \mathrm{mg} / \mathrm{kg} /$ day, prednisolone and azathioprine $(1 \mathrm{mg} / \mathrm{kg} /$ day $)$. Cyclosporine dose was adjusted to keep the CsA trough level between 200 and 400 $\mathrm{ng} / \mathrm{ml}$ in the first 2 months and between 125 and $175 \mathrm{ng} / \mathrm{ml}$ thereafter. The CsA trough level was measured at first using Radio-Immune Assay Kits, Sandoz, Basel, Switzerland, and then using monoclonal specific antibody, Abbott, USA. In $1990 \mathrm{~s}$, tacrolimus $(0.15 \mathrm{mg} / \mathrm{kg}$ twice daily and/or mycophenolate mofetile (MMF) $2 \mathrm{~g} /$ day were introduced as rescue therapy in some cases or to replace either CsA or azathioprine as a result of their side effects. The tacrolimus dose was adjusted to achieve a trough level between 5 and $10 \mathrm{ng} / \mathrm{ml}$.

All acute rejection episodes were documented by histopathological examination and treated by methylprednisolone pulses $500 \mathrm{mg}$ / day for 5 days. Steroid-resistant rejection was treated by antibody therapy, antithymocyte globulin, or orthoclone (OKT3).

\section{Follow-Up Data}

Follow-up data were obtained for all patients and all medical or surgical complications were recorded.

The date of transplant failure was defined as the earliest time of return to chronic dialysis or death with of functioning graft. Patients who had a functioning graft for 15 years or more were compared to kidney transplants in the same period (range 15-24 years) with respect to the following factors: recipient age and sex, donor relation, donor age and gender, HLA-A, -B, -DR mismatching, transplant number, pre-transplant blood transfusions, cause of end-stage kidney disease, primary and secondary immunosuppression, immediate diuresis, ischemia time, frequency and severity of acute rejection episodes, chronic allograft nephropathy, recurrence of original kidney disease and finally medical or surgical complications.

\section{Statistical Analysis}

Statistical analysis was carried out using IBM-compatible computer SPSS/PC for windows version 7.5 (SPSS Inc. Chicago, Ill., USA). For univariate analysis, Student's t test and $\chi^{2}$ test were used. Multivariate analysis was carried out using Cox logistic regression. Differences were compared using the log-rank test. $p<0.05$ was considered significant.

\section{Results}

Demographic characteristics of long-term allograft survivors show that most of the recipients were males in their middle age. Only one donor was aged more than 50 years. The causes of end-stage kidney disease were possible in 41 patients. Histopathological diagnosis of membranous nephropathy was settled in 5 cases and mesangiocapillary glomerulonephritis type 1 in 2 cases.

The immunological variables demonstrated that more than $92 \%$ received grafts from related donors. Unrelated donors were asked in 3 cases - because of hereditary disease such as polycystic kidney ( 2 cases) and hereditary nephritis ( 1 case). More than $88 \%$ of patients received grafts from donors with the same blood group. In our group of long-term allograft survivors, we observed that more than $70 \%$ of patients received pre-transplantation blood transfusion, and more than half of them received between 1 and 5 units.

Acute rejection episodes occurred in 40 patients (64.5\%). Twenty-one patients had one acute rejection episode. The acute rejection episodes were reversed success- 
Table 1. Characteristics of graft surviving group versus non-surviving group in the same transplantation period

\begin{tabular}{|c|c|c|c|}
\hline & $\begin{array}{l}\text { Graft surviving } \\
\text { group } \\
(\mathrm{n}=62)\end{array}$ & $\begin{array}{l}\text { Non-surviving } \\
\text { group } \\
(\mathrm{n}=82)\end{array}$ & $\mathrm{p}$ \\
\hline \multicolumn{4}{|l|}{ Recipient age, years } \\
\hline Mean $\pm \mathrm{SD}$ & $27.5 \pm 6.6$ & $29.5 \pm 9.6$ & 0.2 \\
\hline Range & $9-43$ & $11-47$ & \\
\hline \multicolumn{4}{|l|}{ Intervals } \\
\hline$<20$ & $5(8.1 \%)$ & $19(23.1 \%)$ & \\
\hline $20-30$ & $38(61.3 \%)$ & $29(35.4 \%)$ & \\
\hline $30-40$ & $17(27.4 \%)$ & $21(25.6 \%)$ & 0.001 \\
\hline $40-50$ & $2(3.2 \%)$ & $13(15.9)$ & \\
\hline Recipient sex (M/F) & $43 / 19$ & $57 / 25$ & 0.9 \\
\hline Donor age, years & $30 \pm 8.6$ & $35 \pm 10.7$ & 0.03 \\
\hline Donor sex (M/F) & $31 / 31$ & $37 / 45$ & 0.6 \\
\hline \multicolumn{4}{|l|}{ Consanguinity } \\
\hline Parents & $8(13 \%)$ & $24(29 \%)$ & \\
\hline Siblings & $49(79 \%)$ & $52(63 \%)$ & 0.06 \\
\hline Unrelated & $3(4.8 \%)$ & $6(8 \%)$ & \\
\hline \multicolumn{4}{|l|}{ Original kidney diseases } \\
\hline Chronic interstitial nephritis & $13(21 \%)$ & $12(14.6 \%)$ & \\
\hline Chronic glomerulonephritis & $7(11 \%)$ & $7(8.6 \%)$ & \\
\hline PCK & $2(3.2 \%)$ & $2(2.4 \%)$ & \\
\hline Nephrosclerosis & $1(1.6 \%)$ & $3(3.7 \%)$ & 0.9 \\
\hline Hereditary nephritis & $1(1.6 \%)$ & $2(2.4 \%)$ & \\
\hline Amyloidosis & $1(1.6 \%)$ & $1(1.2 \%)$ & \\
\hline Inapplicable & $19(31 \%)$ & $27(33 \%)$ & \\
\hline \multicolumn{4}{|l|}{ Recipients schistosomal } \\
\hline infection (Yes/No) & $23 / 39$ & $39 / 43$ & 0.2 \\
\hline \multicolumn{4}{|l|}{ Primary immunosuppression } \\
\hline Steroid + azathioprine & $33(53 \%)$ & $50(61 \%)$ & \\
\hline Steroid + CsA & $26(42 \%)$ & $29(35.4 \%)$ & 0.7 \\
\hline Triple & $3(5 \%)$ & $3(3.6 \%)$ & \\
\hline \multicolumn{4}{|l|}{ Secondary immunosuppression } \\
\hline Steroid + azathioprine & $10 / 123$ & $19 / 32$ & \\
\hline Steroid + CsA & $21 / 8$ & $21 / 11$ & 0.9 \\
\hline Ischemia time, $\min ($ mean $\pm \mathrm{SD})$ & $47 \pm 10$ & $48 \pm 9$ & 0.7 \\
\hline Immediate diuresis & $55(89 \%)$ & $63(77 \%)$ & 0.1 \\
\hline ATN & $3(4.8 \%)$ & $11(13 \%)$ & 0.08 \\
\hline \multicolumn{4}{|l|}{ Acute rejection episodes } \\
\hline No & $22(35.5 \%)$ & $24(29.3 \%)$ & \\
\hline One & $21(33.9 \%)$ & $33(40.2 \%)$ & 0.7 \\
\hline Two or more & $19(30.6 \%)$ & $25(30.5 \%)$ & \\
\hline Chronic rejection & $23(37 \%)$ & $63(77 \%)$ & 0.005 \\
\hline \multicolumn{4}{|l|}{ Post-transplant complications } \\
\hline Hypertension & $33(53 \%)$ & $52(72 \%)$ & 0.02 \\
\hline Diabetes mellitus & $14(23 \%)$ & $10(14 \%)$ & 0.2 \\
\hline Infection & $14(23 \%)$ & $10(13.9 \%)$ & 0.3 \\
\hline Malignancy & $4(6.5 \%)$ & $6(7.1 \%)$ & 0.2 \\
\hline Hepatic dysfunction & $4(6.5 \%)$ & $9(12.5 \%)$ & 0.2 \\
\hline Surgical & $3(4.8 \%)$ & $5(6.1 \%)$ & 0.1 \\
\hline
\end{tabular}

fully with the return of serum creatinine levels to baseline in $72 \%$ of the cases.

Post-transplant hypertension $(>150 / 90 \mathrm{~mm} \mathrm{Hg})$ was diagnosed in 33 patients (53\%). Hypertension was more frequent in patients with serum creatinine levels greater than $2 \mathrm{mg} / \mathrm{dl}$, patients treated with CsA than in conventional group (19 vs. $14, \mathrm{p}=0.07$ ).

Post-transplant diabetes mellitus was diagnosed in 14 patients $(23 \%)$. Nine of them had a family history of diabetes mellitus. In 6 patients, insulin therapy was required, 
Table 2. Immunological variables in long-term kidney allograft survivors and non-surviving grafts

\begin{tabular}{llll}
\hline & $\begin{array}{l}\text { Graft surviving } \\
\text { group } \\
(\mathrm{n}=62)\end{array}$ & $\begin{array}{l}\text { Non-surviving } \\
\text { group } \\
(\mathrm{n}=82)\end{array}$ & $\mathrm{p}$ \\
\hline $\begin{array}{lll}\text { Pre-transplant blood transfusion (yes/no) } \\
\text { Blood group (same/different) }\end{array}$ & $45 / 17$ & $60 / 22$ & 0.5 \\
HLA-A, -B matching & $55 / 7$ & $77 / 5$ & 0.3 \\
$\quad$ Zero & - & $1(1.2 \%)$ & \\
One matching & $6(9.7 \%)$ & $7(8.5 \%)$ & \\
Two matchings & $31(50 \%)$ & $38(46.3 \%)$ & 0.2 \\
Three matchings & $19(30.6 \%)$ & $16(19.5 \%)$ & \\
Four matchings & - & $3(3.7 \%)$ & \\
Inapplicable & $6(9.7 \%)$ & $17(20.7 \%)$ & \\
HLA-DR matching & $52(83.8 \%)$ & $56(68.3 \%)$ & \\
One matching & - & - & \\
Two matchings & $10(16.1 \%)$ & $26(31.7 \%)$ & 0.03 \\
Inapplicable & $1(1.6 \%)$ & $2(1.2 \%)$ & 0.1 \\
Retransplantation & &
\end{tabular}

and in 8 patients, diet regimen and oral anti-diabetic agents could control the diabetic state.

Malignancy developed in 4 patients (6.5\%), which included 2 patients with Kaposi's sarcoma, 1 breast carcinoma and 1 cancer of the head of the pancreas. The mean latency period for development of malignancy was $125 \pm$ 62.5 months (range, 36-172 months) post-transplantation.

Fourteen patients (23\%) developed at least one attack of infection during the post-transplantation course. Although the majority of these were upper respiratory tract or urinary tract infections, serious infections were encountered in 5 cases: bacterial pneumonia in three, cytomegalovirus (CMV) in one, and disseminated coccidiomycosis fungal infection in one. Mycobacterium tuberculosis was not diagnosed in our cases.

We compared the long-term surviving patients with patients who were transplanted during the same period and had lost their grafts. The results show that recipient age intervals, donor age, pre- and post-transplant hypertension, chronic rejection and HLA-DR matching have a statistically significant impact on long-term graft survival $(\mathrm{p}<0.05)$. Multivariate analysis demonstrated that recipient age, immediate diuresis and post-transplant hypertension are significant risk factors affecting the long-term allograft survival (table 3).

Patients with long-term renal allograft function were compared according to the primary immunosuppression; conventionally (prednisolone and azathioprine) treated $(n=33)$ and cyclosporine-treated patients $(n=29)$, data
Table 3. Analysis of risk factors for longterm renal allograft survivors

\begin{tabular}{ll}
\hline Univariate analysis & \\
Recipient age & 0.000 \\
Recipients gender & 0.671 \\
Donor age & 0.058 \\
Donor gender & 0.445 \\
Original kidney disease & 0.682 \\
Pre-transplant hypertension & 0.013 \\
Blood transfusion & 0.687 \\
Retransplantation & 0.499 \\
HLA-A, -B matching & 0.691 \\
HLA-Dr matching & 0.362 \\
Ischemia time & 0.456 \\
Time to diuresis & 0.01 \\
ATN & 0.043 \\
Primary Immunosuppression & 0.439 \\
Acute rejection episodes & 0.564 \\
Chronic allograft nephropathy & 0.000 \\
Post-transplant hypertension & 0.000 \\
Post-transplant diabetes mellitus & 0.855 \\
Infection & 0.563 \\
Post-transplant malignancy & 0.120 \\
Urological complications & 0.651 \\
\hline Multivariate analysis & \\
Recipient age & 0.001 \\
Immediate diuresis & 0.024 \\
Post-transplant hypertension & 0.000 \\
& \\
\hline
\end{tabular}

El-Agroudy/Bakr/Hassan/Ismail/ Ali-El-Dein/Shehab El-Dein/Ghoneim 
showed that that post-transplant hypertension is, though not statistically significant, more prevalent in CsA-treated patients $(p=0.07)$, and the mean serum creatinine at the current follow-up visit was statistically significantly higher in the CsA-treated group $(\mathrm{p}<0.05)$.

\section{Discussion}

During the last two decades, significant progress has been achieved in the graft and patient survival rates after renal transplantation [2]. Among nearly 100,000 renal transplants performed between 1982 and 1996 in the United States, the half-life for cadaver and living-related allografts had improved to 13.8 and 21.6 years, respectively [6]. In our center, the first renal graft was implanted in March, 1976 and since then more than 1,350 livedonor kidney transplantations were performed. Therefore, the true success of organ grafting should be judged by its long-term benefit to patients and we have analyzed the results of all patients who received successful kidney grafts that functioned for 15 years or more.

Our results show a 15 -year graft survival rate of $43 \%$. Tanabe et al. [7], found that 719 CsA-treated kidney transplant recipient out of a total of $1,024(70 \%)$ had functioning grafts at the end of the observation period, from 1.6 up to 14.5 years, while Kyllonen et al. 2001 [8], reported on 107 patients of 824 kidney transplants (15\%) who had functioning grafts for longer than 20 years.

The incidence of various long-term complications seen in our series is similar to those reported previously in patients with graft survival of 10 years or more [9-13]. Hypertension was the most common complication that occurred in $53 \%$ of the patients. The overall prevalence of hypertension among kidney transplant recipients ranges in most series between 70 and $80 \%[14,15]$. In our series, we observed that post-transplant hypertension was more prevalent in CsA-treated patients, and in parallel with rising serum creatinine. Long-term allograft and patient survival may be negatively influenced by post-transplant hypertension. In a large study of nearly 30,000 renal transplant recipients the presence of hypertension was significantly associated with allograft loss [15]. Our data prove that post-transplant hypertension has a deleterious effect on renal allograft survival by univariate and multivariate analysis. Several reports described the role of pre-transplantation hypertension in the development of hypertension after transplantation [15].

Post-transplant infections were common among our long-term allograft survivors (23\%). Urinary tract infec- tion was the most common infection, and had no significant morbidity. Severe bacterial pneumonia was responsible for mortality in all cases that died with functioning grafts. Hence, while death with a functioning graft was responsible for graft failure in only $8 \%$ in our series, posttransplant infection still contributed strongly to this mortality. In reviewing the cause of death after transplantation, Briggs [15], found that infection in the recent past accounted for $15-20 \%$ of deaths following transplantation. It may be argued that even with our patient selection, prophylactic measures and effective treatment, the rate of infection is still high in our patients, which may be attributed to the bad habits related to the low socioeconomic status and poverty of some of the people in our developing country.

Although diabetes mellitus developed in 14 patients (23\%) during the post-transplantation course, it had no significant impact on graft survival. Interestingly, 1 patient developed de novo diabetic glomerulosclerosis 12 years after the diagnosis of diabetes.

In our series, there was a noticeable effect of recipient and donor age, HLA-DR mismatching, pre- and posttransplantation hypertension, and chronic allograft nephropathy on the long-term graft outcome. These results obtained were comparable with others [16-27] but with some conflicting data which may be related to the center effect or difference between living and cadaveric renal transplant outcome.

Although several studies implicate acute rejection as the major risk factor for chronic allograft failure $[6,13$, $16,18]$, not all other studies agree [19, 25-27]. Berczi et al. [26] reported that a single acute rejection in the early post-transplant period has no major effect on long-term graft survival. Verghese [20], in 1999, found that there was a well-documented relationship between the intensity, frequency, late rejection and resolution of prior episodes of acute rejection and long-term chronic allograft dysfunction. In our patients, though they had a lower frequency and severity of acute rejection episodes, they did not reach statistically significance. Moreover, most of these episodes, in the survival group, were in the early period after transplantation. Long-term allograft success occurred in spite of these early acute rejection episodes at that time, may be related to the better correlation between the increase in serum creatinine and acute rejection in the pre-cyclosporine era, thus facilitating early diagnosis and successful treatment of these episodes.

The issue of HLA matching and long-term graft survival in living-related donor transplantation is still not clear. Our data show a significant impact of DR matching and 
long-term graft survival but a poor correlation between HLA-A and -B matching and graft survival. Many authors did not find a correlation between HLA-A, -B matching and long-term survival in living donor kidney transplantation $[18,29,30]$, while some studies confirm this correlation [31, 32].

Recipient age is another factor said to influence longterm graft survival. In the UNOS registry report, they found that recipients over the age 60 years and under the age of 19 had poorer graft survival, and when the recipients was over age 60 years, more than $60 \%$ of graft failure were accounted for by death with graft function [33]. In living-related renal transplants these findings could be confirmed [18], while the same trend was not argued by some other authors [29]. The determinant effect of recipient age could be elucidated by our study on long-term survivors by multivariate analysis.

Kidney transplants from older live donors is sill controversial [18, 27, 32]. In our series of graft surviving patients, we could confirm that donor age was a significant predictor of graft survival by univariate analysis. It has been accepted that declining nephron mass in the aged kidney may limit the functional life term of the older donor's kidneys.

The initial immunosuppressive protocols regardless of protocol changes that were made later was analyzed in the graft-surviving group (intension to treat). Patients on cyclosporine-based immunosuppression clearly didn't show any significant benefit on long-term graft survival than patients on azathioprine and steroids $(\mathrm{p}=0.7)$. Our data are in agreement with many other studies [35, 36] which make it clear that CsA has contributed to the dramatic improvement of 1-year graft outcome, but its impact on long-term graft survival is questionable.

In conclusion, renal transplantation, even in its earliest years and despite the numerous complications, has provided 15 or more years of near-normal life to patients with end-stage renal disease, who otherwise would have been dialysis dependent. In our series, the chronic allograft nephropathy constitutes the most important cause of graft loss. Interestingly, young donor/young recipient pairs with good DR matching were significantly more frequent long-term allograft survivors with less pre- and post-transplantation prevalence of hypertension which may reflect the better general conditions of these kidney recipients. For recipients with early acute rejection, favorable histological results and return of serum creatinine levels to baseline have been reported to predict good long-term graft outcome.

As with any retrospective study, the present results should be interpreted with caution. In retrospective analysis, it is always difficult to know when clinical associations represent true cause-and-effect relationships. Nevertheless, our results suggest a number of factors, which may effect long-term renal allograft survival. These factors may define patients who are most likely to develop chronic allograft dysfunction and may make it possible to select high-risk patients for potential therapeutic interventions.

\section{References}

1 Fletcher SM, Novick AC, Braun WE, Popowaniak KL, Steinmuller D: Functional capacity and rehabilitation of recipients with a functioning renal allograft for ten years or more Transplantation 1983;35:572-577.

2 Terasaki PI, McClelland ID, Yuge J, Cecka MJ, Gjertson DW, Takemoto S, Cho YW: Advances in kidney transplantation 1985-1995; in Cecka JM, Terasaki PI (eds): Clinical Transplants 1995. Los Angeles, UCLA Tissue Typing Laboratory, 1996, pp 487-501.

3 Ghoneim MA, Sobh MA, Shokeir A, Bakr MA, Sherif AK, Foda MA: Prospective randomized study of azathioprine versus cyclosporine in live donor kidney transplantation. Am J Nephrol 1993;13:437-441.

4 Bakr MA, Sally S, Foda MA, Sobh MA, Sherif AK, Ghoneim MA: Different trends in immunosuppression: 10 years experience with cyclosporine after living related donor renal transplantation. Transplant Proc 1994;26: 3163-3166.
5 Sobh MA, El-Agroudy A, Moustafa F, Harras F, El-Bedewy M, Ghoneim MA: Co-administration of ketoconazole to cyclosporine treated kidney transplant recipients: A prospective randomized study. Am J Nephrol 1995;15: 493-499.

6 Hariharan S, Johnson CP, Bresnahan BA, Taranto $\mathrm{SE}, \mathrm{Mc}$ Intosh $\mathrm{MJ}$, Stablein D: Improved graft survival and renal transplantation in the United States, 1988 to 1996 . N Engl J Med 2000;342:605-612.

7 Tanabe K, Ishikawa N, Tokumoto T, Tokahashi K, Oshima T, Fuchinouc S, Toma H: Factor's affecting long-term allograft survival in cyclosporine-treated kidney transplants. Transplant Proc 1998;30:1805-1809.

8 Kyllonen L, Koshimies S, Salmela K: Renal transplant recipients with graft survival longer than 20 years: Report on 107 cases. Transplant Proc 2001;33:2444-2445.
9 Silkensen JR: Long-term complications in renal transplantation. JASN 2000;11:582-589.

10 Mahony JF: Long-term results and complications of transplantation: The kidney. Transplant Proc 1989;21:1433-1434.

11 Gueco IP, Evans BD, Calne RY: Prolonged survival after renal transplantation: A study of 54 patients who lived ten or more years after operation with functioning allografts. Transplant Proc 1985;17:108-109.

12 Markell M: Clinical Impact of post-transplant diabetes mellitus. Transplant Proc 2001; 33(suppl A):19S-22S.

13 Golbabaic M, Kayedi M, Nojafi I, Ganji MR, Naderi H, Mehraban D, Hakemi M: Chronic renal allograft dysfunction: Immunologic and nonimmunologic risk factors. Transplant Proc 2001;33:2691-2692.

14 Manage KC, Cizman B, Jaffe M, Feldman HI: Arterial hypertension and renal allograft survival. JAMA 2000;283:633-637. 
15 Briggs ID: Causes of death after renal transplantation. Nephrol Dial Transplant 2001;116: 1545-1549.

16 Ojo AO, Hanson JA, Wolfe RA, Leichtman AB, Agodoa LY, Port FK: Long-term survival in renal transplant recipients with graft function. Kidney Int 2000;57:307-313.

17 McLaren AJ, Fuggle SV, Welsh KI, Gray DWR, Morris PJ: Chronic allograft failure in human renal transplantation: A multivariate risk factor analysis. Ann Surg 2000;232:28-32.

18 Ben Hamida F, Ben Abdallah T, Abdelmoula M, Mejiri H, Gouch R, Abderrahim E, ElYounsi F, Hedri H, Ben Moussa F, Kheder MA, Ben Maiz H: Impact of donor/recipient gender, age, and HLA matching on graft survival following living-related renal transplantation. Transplant Proc 1999;31:3338-3339.

19 Meier-Kriesche H, Ojo AO, Cibrik DM, Hanson JA, Leichtman AB, Magee JC, Part FK, Kaplan B: Relationship of recipient age and development of chronic allograft failure. Transplantation 2000;70:306-310.

20 Varghese Z: Immunologic and nonimmunologic correlates of chronic renal allograft dysfunction. Transplant Proc 1999;31:33563358.

21 Paul LC: Chronic renal transplant loss. Kidney Int 1995;47:1491-1499.

22 Jindal RM, Haricharan S: Chronic rejection in kidney transplants. Nephron 1999;83:13-24.
23 Matas AJ, Gillingham KJ, Humar A, Dunn DL, Sutherland DER, Najarian JS: Immunologic and nonimmunologic factors: Different risks for cadaver and living donor transplantation. Transplantation 2000;69:54-58.

24 Prommool S, Jhangri GS, Cockfield SM, Halloran PF: Time dependency of factors affecting renal allograft survival. JASN 2000;11:565569.

25 Berczi C, Asztalos L, Kincses Z, Locsey L, Balazs G: Effect of acute rejection episodes on long-term renal graft survival. Transplant Proc 1998;30:1775.

26 Lehtonen S, Isoniemi H, Salmela K: Long-term graft outcome is not necessarily affected by delayed onset of graft function and early acute rejection. Transplantation 1997;64:103-108.

27 Ashraf S, Parrott N, Dyer P: Clinical response and temporal patterns of acute cellular rejection: Relationship to chronic transplant nephropathy. Transplant Int 1998;11:5-10.

28 Shaheen FAM, AlSulaiman M, Mousa D, ElDin ABS, Hawas F, Fallatah A, Bill P, Sheikh IA, Al Menawy L, Ramprasad KS, Al Khader AA: Impact of donor/recipient gender age HLA matching and weight on short-term graft survival following living related renal transplantation. Transplant Proc 1998;30:3655-3658.
29 Klein T, Shapira Z, Bar Nathan N, Shaharabani E, Or H, Zakai C, Shabtal E, Yussi A: Lack of correlation between HLA match and longterm survival in living donor kidney transplantation. Transplant Proc 2000;32:692-693.

30 Hata Y, Ozawa M, Takemoto S: HLA matching; in Terasaki PI (ed): Clinical Transplants 1996. Los Angeles, UCLA Tissue Typing Laboratory, 1997, pp 381-388.

31 Zafar N, Hafiz S, Khan S, Abbas K, Ahmed S, Aziz T, Shaikh R, Abidis F, Ahmed N, Naqvi A, Rizvi A: Histocompatibility in live related donor renal transplantation. Transplant Proc 1997;29:2973-2974.

32 Cecka JM: The UNOS scientific renal Transplant registry. Clin Transplant 1998;1:1-11.

33 Kouli F, Morrel CH, Ratner EL, Kraus ES Impact of donor recipient traits independent of rejection on long-term renal function. Am J Kid Dis 2001;37:356-359.

34 Opelz G, Wujciak T, Ritz E, for the Collaborative Transplant Study. Association of chronic kidney graft failure with recipient blood pressure Kidney Int 1998;53:217-223.

35 Vanrenterghem YF: Approaches to improving long-term allograft outcome. Transplant Proc 1998;30(suppl 8A):2S-6S.

36 Opelz G, for the Collaborative Transplant Study: Effect of immunosuppressive therapy on graft half-life projections. Transplant Proc 1999;31(suppl 7A):31S-33S 